\title{
SUBSTANCES STIMULATING GLUCOSE CATABOLISM BY THE OXIDATIVE REACTIONS OF THE PENTOSE PHOSPHATE PATHWAY IN HUMAN ERYTHROCYTES *
}

\author{
By ARIEH SZEINBERG † AND PAUL A. MARKS \\ (From the Department of Medicine, College of Physicians and Surgeons, Columbia University, \\ New York, N. Y.)
}

(Submitted for publication January 9, 1961; accepted February 3, 1961)

Mature human erythrocytes possess the enzymes necessary to catabolize glucose to $\mathrm{CO}_{2}$ via pentose phosphate pathway or to lactic acid via the Embden-Meyerhof pathway. These cells are deficient in certain enzymes of the tricarboxylic acid cycle. In the non-nucleated red cells, the oxidative reactions of pentose phosphate pathway appear to be the sole mechanism for glucose conversion to $\mathrm{CO}_{2}$ and for the generation of TPNH $(2,3)$. Several investigators have suggested that a major factor in the control of the rate of glucose catabolism via the pentose phosphate pathway is the metabolic demand for TPNH (4-6). It has been demonstrated that addition of dyes capable of acting as electron acceptors from TPNH (i.e., methylene blue, phenazine methosulphate, pyocyanin) increases the rate of activity of this pathway in erythrocytes, liver slices and mammary glands (7-9). Stimulation of the pentose phosphate pathway by pyruvate in bovine corneal epithelium, by insulin in rat mammary tissue, and by ammonium salts in yeasts has been ascribed to supply of substrates requiring TPNH for their metabolism or to stimulation of enzyme systems which utilize TPNH $(8,10-12)$.

Among the systems requiring TPNH is that involved in the maintenance of glutathione in the reduced state (13). It has been demonstrated that human erythrocytes deficient in glucose-6phosphate dehydrogenase (G6PD) are unable to maintain their level of reduced glutathione upon incubation with a variety of agents, such as acetylphenylhydrazine, primaquine, ascorbic acid, alpha naphthol, nitrofurantoin, cysteine and fava

* This work was supported in part by Grants CY 2332 and RG 7368 of the United States Public Health Service. A preliminary report of a portion of these data has appeared in abstract form (1).

$\dagger$ Visiting Scholar in Medicine. Present address: Government Hospital, Tel Hashomer, Israel. bean extract (14-19). This finding suggests that such substances might produce a relative insufficiency in the supply of TPNH either by inhibiting reactions in which TPNH is generated or by leading to an increase in the requirement for this coenzyme which exceeds the maximal capacity of cells deficient in G6PD. It is possible to distinguish between these mechanisms by determining whether these substances inhibit or stimulate the rate of oxidation of glucose by the reactions of the pentose phosphate pathway.

In this investigation a study has been made of the effect of the physiological substancescysteine, ascorbic acid and pyruvate-and of agents which can cause hemolytic anemia-acetylphenylhydrazine, nitrofurantoin, $\alpha$ - and $\beta$-naphthol, primaquine and fava bean extract - on the rate of glucose oxidation via the pentose phosphate pathway by red cells. Observations have been made with erythrocytes from normal subjects and from persons with a genetically determined deficiency of G6PD. It has been found that these substances increase the oxidation rate of glucose carbon atom 1 to $\mathrm{CO}_{2}$ by red cells, but not the rate of glucose conversion to lactic acid. The stimulatory effect of these substances is much greater with erythrocytes with normal levels of G6PD than with cells from persons with a marked deficiency of this enzyme. The increased rate of glucose oxidation caused by these compounds is not attributable to a direct action on G6PD. Rather, it was found that certain of these substances oxidize TPNH in the presence of diaphorase.

\section{METHODS}

Preparation of erythrocytes. Human venous blood, collected in siliconized tubes containing heparin, was mixed with an equal volume of 3 per cent dextran (Larco, grade $\mathrm{HH}$, mol wt ca. 225,000) and 3 per cent glucose in $0.15 \mathrm{M}$ sodium chloride, for separation of 
erythrocytes from leukocytes and platelets by a method described in detail elsewhere $(20)$. The erythrocytes were washed 3 times with 20 vol of cold $0.15 \mathrm{M}$ sodium chloride solution and resuspended in Krebs-Ringer phosphate buffer, $\mathrm{pH} 7.4$ (21), to a cell concentration of about $4 \times 10^{6}$ per $\mathrm{mm}^{3}$. This erythrocyte suspension was contaminated with not more than 500 leukocytes per $\mathrm{mm}^{3}$ and 10,000 platelets per $\mathrm{mm}^{3}$.

Hemolysates, when employed, were prepared by lysis of 1 vol of washed packed erythrocytes with 4 vol of cold distilled water.

Isotope experiments. Two $\mathrm{ml}$ of the erythrocyte suspension in Krebs-Ringer phosphate buffer was placed in Warburg type flasks equipped with two side-arms. Glucose labeled in positions 1,2 or 6 with $\mathrm{C}^{14}$ and nonlabeled glucose were placed in a side-arm together with additional substances as indicated in the tables. The final volume was made to $3 \mathrm{ml}$ with Krebs-Ringer phosphate buffer. After 10 minutes' equilibration with an appropriate gas, the contents of the side-arm was tipped into the main compartment and incubation carried out at $37^{\circ} \mathrm{C}$ for 2 hours. At the end of this period of incubation, $1.0 \mathrm{ml} 50$ per cent trichloroacetic acid was introduced into the previously used side-arm through the gas vent of the stopper and $0.2 \mathrm{ml}$ hyamine hydroxide and $0.2 \mathrm{ml}$ toluene $(21)$ were placed in the second sidearm. The contents of the side-arm containing the solution of acid was then tipped into the main compartment. Quantitative diffusion of released $\mathrm{C}^{14} \mathrm{O}_{2}$ into the hyamine hydroxide mixture was achieved by shaking the flasks at $37^{\circ} \mathrm{C}$ for 1 hour. The hyamine-toluene mixture was quantitatively transferred into bottles containing $1.0 \mathrm{ml}$ of absolute ethanol and $5.0 \mathrm{ml}$ of 0.3 per cent 2,5-diphenyloxazole and 0.03 per cent $2,2^{\prime}$-p-phenylene-bis-(5-phenyloxazole) in toluene. The assay of radioactivity was performed in a liquid scintillation counter with an efficiency of 60 per cent and a background of $30 \mathrm{cpm}$ (22).

Lactic acid determinations were performed by an enzymatic procedure (23). An aliquot of the trichloroacetic acid extract from the incubation mixtures was centrifuged and the supernatant fluid recovered and adjusted to $\mathrm{pH}$ 10.0 with $1.0 \mathrm{~N} \mathrm{NaOH}$. Assay mixtures were set up in cuvets as follows: $2 \mathrm{ml}$ glycine- $\mathrm{NaOH}$ buffer, $0.2 \mathrm{M}$, $\mathrm{pH} 10.5 ; 0.2 \mathrm{ml} \mathrm{DPN}, 1.5 \times 10^{-2} \mathrm{M} ; 0.2 \mathrm{ml}$ semicarbazide $\mathrm{HCl}, 1.0 \mathrm{M}$ (adjusted to $\mathrm{pH} 10.5$ with $\mathrm{NaOH}$ ) ; $0.4 \mathrm{ml}$ water and $0.2 \mathrm{ml}$ of the test solution. The optical density at $340 \mathrm{~m} \mu$ of each assay mixture was determined, and $0.050 \mathrm{ml}$ lactic acid dehydrogenase (twice recrystallized, Nutritional Biochemicals Corp.) was added and the change in optical density at $340 \mathrm{~m} \mu$ was followed until no further increase was observed. As standards, solutions of lithium lactate of known concentration were assayed with each set of determinations. In preliminary experiments it was established that cysteine, ascorbic acid, acetylphenylhydrazine, nitrofurantoin, $\alpha$-naphthol and primaquine in the concentrations used in these studies did not interfere with the determination of lactic acid.

Glucose was estimated in barium hydroxide filtrates (24) by the O-amino-diphenyl method of Timell, Glaudemans and Currie (25). This procedure was chosen be- cause none of the compounds studied, with the exception of acetylphenylhydrazine, interfered with the color reaction. Glucose could not be estimated in the presence of acetylphenylhydrazine by this procedure or by the anthrone method (26), by the iodometric titration method of Hagedorn-Jensen (27) or by an enzymatic procedure using "Glucostat" reagents of Worthington Biochemical Corporation (28).

G6PD and 6-phosphogluconic dehydrogenase activities were assayed spectrophotometrically $(29,30)$. A unit of enzyme activity is defined as the amount of enzyme required to give an increase in optical density of 0.001 per minute at $340 \mathrm{~m} \mu$ (31). Erythrocytes from normal subjects assayed by this method had an activity of glucose-6-phosphate dehydrogenase of 10,000 to 20,000 $\mathrm{U}$ per $\mathrm{g}$ hemoglobin, while those from subjects with a fully expressed hereditary deficiency of this enzyme, 500 to $4,000 \mathrm{U}$ per $\mathrm{g}$ hemoglobin.

Materials. Erythrocyte G6PD was purified from normal human erythrocytes by a method described in detail elsewhere (32). Spinach TPNH diaphorase was prepared according to the method of Avron and Jagendorf (33). An extract of fava bean was prepared by the method of Walker and Bowman (18). G6PD partially purified from yeast and a preparation of diaphorase prepared from Clostridium kluyveri were purchased from Sigma Chemical Corp. Primaquine phosphate was kindly provided to us by Winthrop Laboratories and nitrofurantoin [N(5-nitro-2-furfurylidene)-1-aminohydantoin] by Eaton Laboratories.

\section{RESULTS}

\section{Stimulation of glucose oxidation to $\mathrm{CO}_{2}$}

Incubation of normal erythrocytes with cysteine, ascorbic acid, acetylphenylhydrazine, primaquine, nitrofurantoin, $\alpha$ - or $\beta$-naphthol is associated with a 3- to 18 -fold increase in the rate of $\mathrm{C}^{14} \mathrm{O}_{2}$ formation from glucose-1- $\mathrm{C}^{14}$ (Table I). A consistently smaller increase in the rate of $\mathrm{C}^{14} \mathrm{O}_{2}$ formation is observed upon incubation of G6PD-deficient red cells under the same conditions. In the absence of added compounds, the rate of glucose oxidation to $\mathrm{C}^{14} \mathrm{O}_{2}$ is similar in normal and G6PD-deficient cells.

The increased rate of $\mathrm{C}^{14} \mathrm{O}_{2}$ formation in the presence of these compounds is not caused by an action of these agents directly on glucose. This is indicated by the observation that when glucose$1-\mathrm{C}^{14}$ is incubated with these compounds without added erythrocytes or with boiled suspensions of erythrocytes no $\mathrm{C}^{14} \mathrm{O}_{2}$ is formed.

The increase in the rate of oxidation of glucose to $\mathrm{C}^{14} \mathrm{O}_{2}$ in the presence of these substances involves glucose-6-phosphate (G6P) which is re- 
TABLE I

Effect of various compounds on the rate of $\mathrm{C}^{14} \mathrm{O}_{2}$ formation from glucose-1-C $C^{14}$ by erythrocytes of normal and G6PD-deficient subjects

\begin{tabular}{|c|c|c|c|c|c|c|c|}
\hline \multirow[b]{3}{*}{ Compound added* } & \multirow[b]{3}{*}{ Concentration } & \multicolumn{3}{|c|}{ Cells from normal subjects $\dagger$} & \multicolumn{3}{|c|}{ Cells from mutant subjects $\dagger$} \\
\hline & & \multirow{2}{*}{$\begin{array}{l}\text { No. of } \\
\text { exp. }\end{array}$} & \multicolumn{2}{|c|}{ Activity of $\mathrm{C}^{14} \mathrm{O}_{2}$} & \multirow{2}{*}{$\begin{array}{l}\text { No. of } \\
\text { exp. }\end{array}$} & \multicolumn{2}{|c|}{ Activity of $\mathrm{C}^{14} \mathrm{O}_{2}$} \\
\hline & & & Range & Mean & & Range & Mean \\
\hline & $M$ & \multicolumn{3}{|c|}{$\mu c \times 10^{-3} / 10^{9} R B C$} & & \multicolumn{2}{|c|}{$\mu c \times 10^{-3} / 10^{9} R B C$} \\
\hline None & & 9 & $0.28-0.75$ & 0.41 & 8 & $0.16-0.52$ & 0.35 \\
\hline Methylene blue & $1.6 \times 10^{-4}$ & 8 & $7.9-25.1$ & 16.7 & 6 & $1.8-5.2$ & 4.0 \\
\hline Cysteine & $3.5 \times 10^{-2}$ & 4 & $4.1-7.1$ & 5.8 & 4 & $1.5-2.7$ & 2.0 \\
\hline Ascorbic acid & $2.8 \times 10^{-2}$ & 4 & $6.2-7.7$ & 6.9 & 3 & $1.5-3.8$ & 2.6 \\
\hline Acetylphenylhydrazinef & $3.3 \times 10^{-2}$ & 5 & $2.8-5.7$ & 3.6 & 4 & $0.9-1.5$ & 1.3 \\
\hline$\alpha$-Naphtholf & $6.9 \times 10^{-3}$ & 6 & $3.2-5.5$ & 4.4 & 4 & $0.9-2.4$ & 1.7 \\
\hline$\beta$-Naphtholf & $6.9 \times 10^{-3}$ & 3 & $3.0-5.8$ & 4.1 & 3 & $1.6-2.1$ & 1.8 \\
\hline Primaquine phosphate & $7.8 \times 10^{-3}$ & 7 & $0.8-2.5$ & 1.6 & 4 & $0.43-0.90$ & 0.64 \\
\hline Nitrofurantoin $\ddagger$ & $4.2 \times 10^{-3}$ & 6 & $2.4-3.3$ & 2.7 & 3 & $0.87-2.1$ & 1.3 \\
\hline
\end{tabular}

* Ascorbic acid and cysteine were added as neutralized solutions in Krebs-Ringer phosphate buffer. The other compounds were added as dry powders. Final glucose concentration, $1 \times 10^{-2} \mathrm{M}$; amount of glucose-1-C ${ }^{14}$ added, $0.6 \mu \mathrm{c} /$ flask; erythrocytes added, 6.9 to $9.0 \times 10^{9}$ flask; gas phase, $100 \%$ oxygen; incubation time, 2 hours.

$\dagger$ Normal subjects had red cell G6PD activities between 10,000 and 20,000 U/g hemoglobin. Each compound was assayed with erythrocytes of one mutant Caucasian female of Spanish extraction and a number of Negro mutants. The G6PD activity in erythrocytes of all these subjects was 1,000 to $4,000 \mathrm{U} / \mathrm{g}$ hemoglobin.

$\ddagger$ These compounds are only slightly soluble in water. Their solubility in the incubation mixture used in these experiments is not known. Accordingly, the concentrations indicated represent calculations based on the amounts added and not necessarily on the amounts actually in solution.

cycled via pentose phosphate, as well as G6P formed from glucose. Addition of the various compounds to erythrocytes incubating with glucose-2- $\mathrm{C}^{14}$ is associated with an increased rate of $\mathrm{C}^{14} \mathrm{O}_{2}$ formation (Table II). In fact, in the presence of cysteine, ascorbic acid and acetylphenylhydrazine, the relative increase in the rate of $\mathrm{C}^{14} \mathrm{O}_{2}$ formation from glucose-2- $\mathrm{C}^{14}$ is higher than that from glucose-1-C ${ }^{14}$. When none of these compounds is added, the ratio of the rate of formation of $\mathrm{C}^{14} \mathrm{O}_{2}$ from glucose-1-C ${ }^{14}$ to that from glucose$2-\mathrm{C}^{14}$ is about 6 , while in the presence of these compounds it decreased to about 2 . A similar de- crease in this ratio is observed in the presence of methylene blue. This is in agreement with the report of Brin and Yonemoto (7). The decrease in the ratio of the rate of $\mathrm{C}^{14} \mathrm{O}_{2}$ formed from glucose-1- $\mathrm{C}^{14}$ to that from glucose-2- $\mathrm{C}^{14}$ suggests that the stimulation of the recycling of pentose phosphate to G6P is greater than the stimulation of glucose carbon 1 oxidation. The present data provide no explanation of the mechanism of this effect.

Incubation of erythrocytes with glucose-6- $\mathrm{C}^{14}$ is associated with negligible amounts of $\mathrm{C}^{14} \mathrm{O}_{2}$ formation. Addition of methylene blue, cysteine, as-

TABLE II

Influence of various compounds on the rates of $\mathrm{C}^{14} \mathrm{O}_{2}$ formation from glucose-1-C $\mathrm{C}^{14}$ and glucose-2- $C^{14}$ by normal erythrocytes *

\begin{tabular}{|c|c|c|c|}
\hline \multirow[b]{2}{*}{ Compounds added } & \multicolumn{2}{|c|}{ Activity of $\mathrm{C}^{14} \mathrm{O}_{2}$ recovered from } & \multirow{2}{*}{$\begin{array}{l}\text { Ratio of } \mathrm{C}^{14} \mathrm{O}_{2} \\
\text { from glucose-1-C } \\
\text { to } \mathrm{C}^{14} \mathrm{O}_{2} \text { from } \\
\text { glucose-2-C }\end{array}$} \\
\hline & Glucose-1-C14 & Glucose-2- $\mathrm{C}^{14}$ & \\
\hline \multicolumn{4}{|c|}{$\mu c \times 10^{-3} / 10^{9} R B C$} \\
\hline $\begin{array}{l}\text { None } \\
\text { Methylene blue } \\
\text { Cysteine } \\
\text { Ascorbic acid } \\
\text { Acetylphenylhydrazine } \\
\alpha \text {-Naphthol } \\
\text { Primaquine phosphate } \\
\text { Nitrofurantoin }\end{array}$ & $\begin{array}{c}0.54 \\
10.2 \\
6.4 \\
7.0 \\
3.1 \\
4.0 \\
1.5 \\
2.8\end{array}$ & $\begin{array}{l}0.09 \\
5.0 \\
3.0 \\
3.5 \\
1.4 \\
0.6 \\
0.37 \\
0.48\end{array}$ & $\begin{array}{l}6.0 \\
2.1 \\
2.1 \\
2.0 \\
2.2 \\
6.6 \\
4.0 \\
5.8\end{array}$ \\
\hline
\end{tabular}

* Conditions of experiment are as in Table I. Glucose-1- $\mathrm{C}^{14}$ or glucose-2-C $\mathrm{C}^{14}, 0.6 \mu \mathrm{c}$, was added to each flask. The results represent mean values of 3 experiments. 
corbic acid, acetylphenylhydrazine, primaquine, nitrofurantoin or $\alpha^{-}$- or $\beta$-naphthol to such incubation mixtures causes no detectable increase in the rate of glucose-6-C $\mathrm{C}^{14}$ oxidation to $\mathrm{C}^{14} \mathrm{O}_{2}$. These observations are consistent with the fact that mature erythrocytes are lacking in the activity of certain enzymes of the tricarboxylic acid cycle (34). In addition, these data suggest that in mature red cells glyceraldehyde-3-phosphate which may be formed in the transketolase reaction is converted to a very limited extent, if at all, to carbon atoms 1 through 3 of G6P.

\section{Oxygen dependence of the stimulatory effect}

Stimulation of the $\mathrm{C}^{14} \mathrm{O}_{2}$ formation by the various compounds is less striking upon incubation of red cells in an atmosphere of air or nitrogen than in 100 per cent oxygen. The stimulatory effect was least marked when the cells were pretreated with carbon monoxide and then incubated in an atmosphere of 100 per cent nitrogen (Table III). The response to such treatment varied with different compounds, the stimulation by acetylphenylhydrazine is almost completely abolished, while that by nitrofurantoin is only little affected.

\section{Effect of concentration of the stimulating com- pounds}

The magnitude of stimulation in the rate of oxidation of glucose-1-C $\mathrm{C}^{14}$ to $\mathrm{C}^{14} \mathrm{O}_{2}$ is related to the

TABLE III

Effect of treatment with carbon monoxide followed by incubation in atmosphere of nitrogen on the rate of $\mathrm{C}^{14} \mathrm{O}_{2}$ formation from glucose-1-C ${ }^{14}$ by normal erythrocytes *

\begin{tabular}{lcc}
\hline & \multicolumn{2}{c}{$\begin{array}{c}\text { Activity of } \mathrm{C}^{14} \mathrm{O}_{2} \\
\text { recovered from }\end{array}$} \\
\cline { 2 - 3 } \multicolumn{1}{c}{ Compound added } & $\begin{array}{c}\text { Control } \\
\text { cells } \\
(\mathrm{gas} \text { phase, } \\
100 \% \mathrm{O}_{2} \text { ) }\end{array}$ & $\begin{array}{c}\text { CO-treated } \\
\text { cells } \\
\text { (gas phase, } \\
100 \% \text { N2) }\end{array}$ \\
\hline None & $\mu c \times 10^{-3} / 10^{\circ}$ & $R B C$ \\
Methylene blue & 0.51 & 0.11 \\
Cysteine & 15.4 & 5.4 \\
Ascorbic acid & 5.6 & 1.3 \\
Acetylphenylhydrazine & 7.0 & 1.4 \\
$\alpha$-Naphthol & 3.1 & 0.3 \\
Primaquine phosphate & 4.3 & 1.5 \\
Nitrofurantoin & 1.7 & 0.66 \\
& 2.8 & 1.9 \\
\hline
\end{tabular}

* Conditions of experiment are as in Table I. The $\mathrm{CO}$-treated cells were obtained by passing carbon monoxide through the suspension of erythrocytes for 10 minutes before distribution into the flasks. The results represent mean values of 3 experiments.
TABLE IV

Effect of plasma and of pyruvate on the rate of $\mathrm{C}^{14} \mathrm{O}_{2}$ formation from glucose-1-C $C^{14}$ by normal cells *

\begin{tabular}{lcc}
\hline \hline \multicolumn{1}{c}{ Addition } & Concentration & $\begin{array}{c}\text { Activity of } \\
\mathrm{C}^{44} \mathrm{O}_{2}\end{array}$ \\
\hline & $M$ & $\mu c \times 10^{-3} /$ \\
None & & $10^{9} R B C$ \\
Plasma $\dagger$ & & 0.47 \\
Sodium pyruvate & $1 \times 10^{-3}$ & 1.15 \\
& $1 \times 10^{-2}$ & 0.95 \\
& & 1.4
\end{tabular}

* Conditions of experiment were described in Table I. The results represent mean values of 3 experiments.

t In the experiment with plasma, the Krebs-Ringer phosphate buffer was replaced by $2 \mathrm{ml}$ homologous cell-free plasma. Control flasks containing plasma alone did not show any $\mathrm{C}^{14} \mathrm{O}_{2}$ formation.

concentration of the added compound. The concentration of the compounds at which maximal stimulation is observed is indicated in Table I. Increasing the concentration beyond the optimal point is associated with a decrease in the degree of stimulation. The maximal effect obtained with cysteine and ascorbic acid is observed at concentrations of these substances 500 times that in normal blood (which is 0.6 to $1.0 \times 10^{-4} \mathrm{M}$ ) (35). However, a twofold increase in the rate of $\mathrm{C}^{14} \mathrm{O}_{2}$ formation is observed upon addition of these compounds in concentrations of $3 \times 10^{-4} \mathrm{M}$.

The low rate of oxidation of glucose-1- $\mathrm{C}^{\mathbf{1 4}}$ to $\mathrm{C}^{14} \mathrm{O}_{2}$ which is observed when washed red blood cells are incubated in a Krebs-Ringer phosphate buffer might in part reflect a depletion of certain substances during the preliminary washing of the cells. Washed erythrocytes resuspended in plasma have a higher rate of oxidation of glucose-1- $\mathrm{C}^{14}$ to $\mathrm{C}^{14} \mathrm{O}_{2}$ than do the same cells suspended in buffer solution (Table IV). This observation is in accord with that of Murphy (2). It is possible that this effect of plasma may be attributed to its content of substances such as ascorbic acid or cysteine, which stimulate the rate of glucose catabolism via the pentose phosphate pathway. There are, of course, other possible explanations for this effect of plasma and the problem requires further study.

\section{Glucose utilization and lactic acid formation in presence of the stimulating compounds}

The increased rate of glucose oxidation via the pentose phosphate pathway in the presence of the various compounds is not associated with an increase in glucose catabolism via the Embden- 
TABLE V

Effect of various compounds on glucose utilization and lactic acid formation by normal erythrocytes *

\begin{tabular}{|c|c|c|}
\hline Compound added & $\begin{array}{l}\text { Lactic acid } \\
\text { formed }\end{array}$ & $\begin{array}{l}\text { Glucose } \\
\text { utilized }\end{array}$ \\
\hline & \multicolumn{2}{|c|}{ umoles $/ 10^{9} R B C / 2$ hrs } \\
\hline None & 1.15 & 0.61 \\
\hline Methylene blue & 0.92 & 0.72 \\
\hline Ascorbic acid & 0.93 & 0.69 \\
\hline Cysteine & 0.97 & 0.59 \\
\hline Acetylphenylhydrazine & 0.62 & $t$ \\
\hline$\alpha$-Naphthol & 0.50 & 0.60 \\
\hline Primaquine phosphate & 0.25 & 0.63 \\
\hline Nitrofurantoin & 1.00 & 0.60 \\
\hline
\end{tabular}

* Conditions of experiment are as in Table I. The results represent mean values of 4 experiments.

$\dagger$ Glucose utilization was not measured owing to lack of a method free from interference by acetylphenylhydrazine.

Meyerhof pathway. In the presence of the stimulating compounds, no comparable increase in the rate of glucose disappearance or lactic acid formation is observed (Table V). On the contrary, under these conditions, a decrease in the rate of lactic acid formation is generally found. Primaquine, acetylphenylhydrazine and $\alpha$-naphthol cause a particularly significant decrease in the rate of lactic acid formation without a similar change in the rate of glucose utilization. This finding suggests that these compounds may inhibit some step in the conversion of glucose to lactic acid beyond G6P.

Stimulation of the oxidation of glucose to $\mathrm{CO}_{2}$ by pyruvate

The addition of pyruvate to the incubation medium causes an increase in the rate of oxidation of glucose-1- $\mathrm{C}^{14}$ to $\mathrm{C}^{14} \mathrm{O}_{2}$ by red cells. Several in- vestigators working with other tissues, have reported that pyruvate may stimulate glucose catabolism via the pentose phosphate pathway $(5,10$, 11). It has been suggested that this effect may result from pyruvate acting as an electron acceptor from TPNH in the presence of lactic dehydrogenase. In the present study, no evidence has been obtained that lactic acid dehydrogenase of erythrocytes can reduce pyruvate in the presence of TPNH. Lactic acid dehydrogenase activity has been assayed by the method of Wroblewski and LaDue (36). No activity of this enzyme is demonstrated in hemolysates when TPNH is used as the hydrogen donor over the $\mathrm{pH}$ range of 6.0 to 7.4. Similarly, no evidence has been obtained that the pyruvate stimulation of the rate of oxidation of glucose to $\mathrm{CO}_{2}$ might be mediated by a pyridine nucleotide transhydrogenase. Thus, incubation of a hemolysate with TPNH, DPN and pyruvate does not result in a decrease of optical density at $340 \mathrm{~m} \mu$. This finding suggests that hemolysates are lacking a transhydrogenating enzyme which could lead to DPNH formation and permit the subsequent reduction of pyruvate under these conditions.

\section{Stimulation of the oxidation of glucose to $\mathrm{CO}_{2}$ by extract of Vicia fava}

An increase in the rate of oxidation of glucose$1-\mathrm{C}^{14}$ to $\mathrm{C}^{14} \mathrm{O}_{2}$ is observed upon incubation of erythrocytes with an extract of fava bean (Table VI). In the main, this effect is due to a thermostable constituent of the extract, as a definite in-

TABLE VI

Effect of extract of Vicia fava on the rate of formation of $C^{14} \mathrm{O}_{2}$ from glucose-1-C $C^{14}$ by normal erythrocytes *

\begin{tabular}{|c|c|c|c|c|}
\hline \multirow[b]{2}{*}{ Cells added } & \multicolumn{2}{|c|}{ Unboiled extract } & \multicolumn{2}{|c|}{ Boiled extract $\dagger$} \\
\hline & Extract added & Activity of $\mathrm{C}^{14} \mathrm{O}_{2}$ & Extract added & Activity of $\mathrm{C}^{14} \mathrm{O}_{2}$ \\
\hline & $m l$ & $\mu c \times 10^{-3} /$ vessel & $m l$ & $\mu c \times 10^{-3} /$ vessel \\
\hline Erythrocytest & 0 & 3.1 & 0 & 3.1 \\
\hline Erythrocytesf & 0.25 & 6.9 & 0.25 & 3.1 \\
\hline Erythrocytest & 0.50 & 8.1 & 0.50 & 6.9 \\
\hline Erythrocytesf & 1.0 & 9.0 & 1.0 & 7.2 \\
\hline Boiled erythrocytes $\S$ & 0 & 0 & & \\
\hline Boiled erythrocytes $\S$ & 1.0 & 0.25 & 1.0 & 0 \\
\hline None & 0.25 & 0.12 & 0.25 & 0 \\
\hline None & 1.0 & 0.30 & 1.0 & 0 \\
\hline
\end{tabular}

* Conditions of experiment are as in Table $\mathrm{I}$.

+ The extract of Vicia fava was heated at $100^{\circ} \mathrm{C}$ for $10 \mathrm{~min}$ prior to addition. $\$ 5 \times 10^{9}$ Erythrocytes were added.

$\S$ The erythrocytes were heated at $100^{\circ} \mathrm{C}$ for $10 \mathrm{~min}$ prior to addition. 
TABLE VII

Influence of various compounds on the activity of G6P and 6-phosphogluconic dehydrogenases in hemolysates and of purified G6PD*

\begin{tabular}{|c|c|c|c|c|}
\hline \multirow[b]{2}{*}{ Compound added } & \multirow[b]{2}{*}{ Concentration } & \multirow[b]{2}{*}{$\begin{array}{l}\text { Activity of } \\
\text { purified } \\
\text { G6PD }\end{array}$} & \multicolumn{2}{|c|}{ Activity of hemolysates } \\
\hline & & & G6PD & $\begin{array}{c}\text { 6-Phospho- } \\
\text { gluconic } \\
\text { dehydrogenase }\end{array}$ \\
\hline & & $U / \min$ & $U / \min$ & $U / \min$ \\
\hline None & & 11.0 & 21.1 & 12.0 \\
\hline Cysteine & $1 \times 10^{-2} \mathrm{M}$ & 11.3 & 20.2 & 11.8 \\
\hline Ascorbic acid & $1 \times 10^{-2} \mathrm{M}$ & 10.9 & 21.0 & 12.1 \\
\hline Acetylphenylhydrazine & $1.0 \times 10^{-2} \mathrm{M}$ & 9.5 & 18.0 & 11.8 \\
\hline$\alpha$-Naphthol & $33 \%$ saturated solution $\dagger$ & 6.5 & 14.0 & 11.9 \\
\hline Primaquine & $1.3 \times 10^{-3} \mathrm{M}$ & 9.4 & 19.1 & 11.0 \\
\hline Nitrofurantoin & $33 \%$ saturated solution & 5.4 & 9.7 & 7.3 \\
\hline
\end{tabular}

* The assay mixture contained $0.5 \mathrm{ml} 0.1 \mathrm{M} \mathrm{MgCl}_{2}, 0.1 \mathrm{ml}$ of $2.5 \times 10^{-3} \mathrm{M}$ TPN, $0.5 \mathrm{ml}$ of $0.01 \mathrm{M} \mathrm{G} 6 \mathrm{P}, 0.005 \mathrm{ml}$ G6PD purified from normal human erythrocytes or $0.050 \mathrm{ml}$ hemolysate from a normal subject, $1.0 \mathrm{ml}$ of a solution of the respective test substance in Krebs-Ringer phosphate buffer and water to the final volume of $3.0 \mathrm{ml}$. For 6-phosphogluconic dehydrogenase assay, $0.5 \mathrm{ml}$ of $0.01 \mathrm{M}$ 6-phosphogluconate was added instead of G6P. Saturated solutions of nitrofurantoin and $\alpha$-naphthol were prepared by suspending $10 \mathrm{mg}$ of the respective compounds in $10 \mathrm{ml}$ of KrebsRinger phosphate buffer, shaking the suspensions for 10 minutes at room temperature and then centrifuging them.

$\dagger 33 \%$ Saturated solution indicates that the saturated solution of these compounds was in a threefold dilution in the final reaction mixture.

crease in the rate of $\mathrm{C}^{14} \mathrm{O}_{2}$ formation is observed in the presence of a boiled preparation. The higher rate of $\mathrm{C}^{14} \mathrm{O}_{2}$ formation upon incubation with an unboiled extract requires further elucidation, since a small quantity of $\mathrm{C}^{14} \mathrm{O}_{2}$ was also formed from glucose-1- $\mathrm{C}^{14}$ in the absence of erythrocytes, suggesting that the extract itself contained a system capable of oxidizing glucose to $\mathrm{CO}_{2}$.

Studies of the mechanism of stimulation of glucose catabolism via the pentose phosphate pathway

1) Effect of the stimulatory compounds on the activity of G6PD. The possibility has been investigated that the increase in the rate of glucose oxidation to $\mathrm{C}^{14} \mathrm{O}_{2}$ caused by the various agents may be a consequence of a direct action on the activity of G6PD. No increase in the activity of preparations of this enzyme purified from erythrocytes or of the enzyme in crude hemolysates is observed upon addition of any of the compounds studied (Table VII). In fact, $\alpha$-napththol and nitrofurantoin inhibit G6PD activity, a finding similar to that previously reported by Desforges, Kalaw and Gilchrist (37). Nitrofurantoin also inhibits 6-phosphogluconic dehydrogenase activity.

2) Effect of the stimulatory compounds on TPNH oxidation. The following experiments were performed to determine if the compounds stimulating glucose oxidation via the pentose phos- phate pathway cause a direct or enzyme-mediated oxidation of TPNH.

a) TPNH was added to solutions of cysteine, ascorbic acid, acetylphenylhydrazine, $\alpha$-naphthol, primaquine and nitrofurantoin buffered at $\mathrm{pH}$ 7.4 and the change of optical density at $340 \mathrm{~m} \mu$ followed with time. Of these several compounds, only cysteine causes a non-enzymatic oxidation of TPNH. The rate of oxidation increases (but not by a linear relationship) with rising cysteine concentration to $1.0 \times 10^{-2} \mathrm{M}$. Further increase in cysteine concentration is associated with a fall in the rate of TPNH oxidation.

b) The experiments indicated above were then performed with the addition of a preparation of a TPNH-specific diaphorase purified from spinach leaves or a diaphorase prepared from $\mathrm{Cl}$. kluyveri which had activity with either TPNH or DPNH. The rate of oxidation of TPNH in the presence of cysteine was not influenced by the addition of either of these diaphorase preparations. In the presence of the diaphorase from spinach leaves, addition of nitrofurantoin or $\alpha$-naphthol to a solution of TPNH causes a decrease in optical density at 340 $\mathrm{m} \mu$. This decrease is linear with time and its magnitude is related to the concentration of these compounds and to the diaphorase activity added (Figure 1). The addition of ascorbic acid, primaquine or acetylphenylhydrazine to such a mixture is not associated with a change in optical density at $340 \mathrm{~m} \mu$. In the presence of the dia- 
phorase prepared from $\mathrm{Cl}$. kluyveri, however, a decrease in optical density at $340 \mathrm{~m} \mu$ is observed when ascorbic acid or primaquine, as well as nitrofurantoin or $\alpha$-naphthol is added to a solution of TPNH. The change in optical density in these experiments is also linear with time and related to the concentration of the added compounds (Figure 2) and to the activity of the diaphorase. The difference in the results obtained with the two diaphorase preparations has not been elucidated. In any event, it would appear that the decrease in optical density observed in the presence of these enzymes represents oxidation of TPNH and not its decomposition by these compounds because it may be largely reversed by addition of a system capable of TPN reduction. An experiment demonstrating a reversal of the oxidation of TPNH in the presence of ascorbic acid by a subsequent addition of G6P and G6PD is illustrated in Figure 3. The plateau observed after addition of G6P and G6PD probably represents an equilibrated

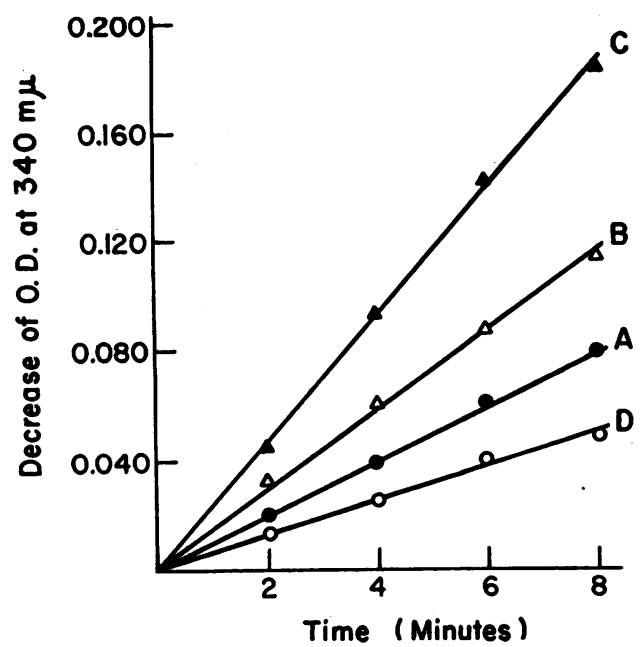

Fig. 1. EFfect of Nitrofurantoin AND $\alpha$-NAPHTHOL ON TPNH OXIDATION IN THE PRESENCE OF SPINACHLEAF DIAPHORASE. The assay mixture contains KrebsRinger phosphate buffer, $0.15 \mu$ mole $\mathrm{TPNH}$, varying volumes of a saturated solution of nitrofurantoin or $\alpha$-naphthol, and diaphorase with an activity of $12 \mathrm{U}$ per $\mathrm{ml}$, prepared from spinach (33). The total volume is $3.0 \mathrm{ml}$ and the incubation is at $24^{\circ} \mathrm{C}$. Curve A, nitrofurantoin $0.100 \mathrm{ml}$, diaphorase $1.2 \mathrm{U}$; curve $\mathrm{B}$, nitrofurantoin $0.25 \mathrm{ml}$, diaphorase $0.6 \mathrm{U}$; curve $\mathrm{C}$, nitrofurantoin $0.25 \mathrm{ml}$, diaphorase $1.2 \mathrm{U}$; curve $\mathrm{D}, \alpha$-naphthol 1.0 $\mathrm{ml}$, diaphorase $1.2 \mathrm{U}$. Control assay mixtures which contain: 1) TPNH and diaphorase, 2) TPNH and nitrofurantoin or $\alpha$-naphthol, and 3) diaphorase and nitrofurantoin or $\alpha$-naphthol, show no change of optical density.

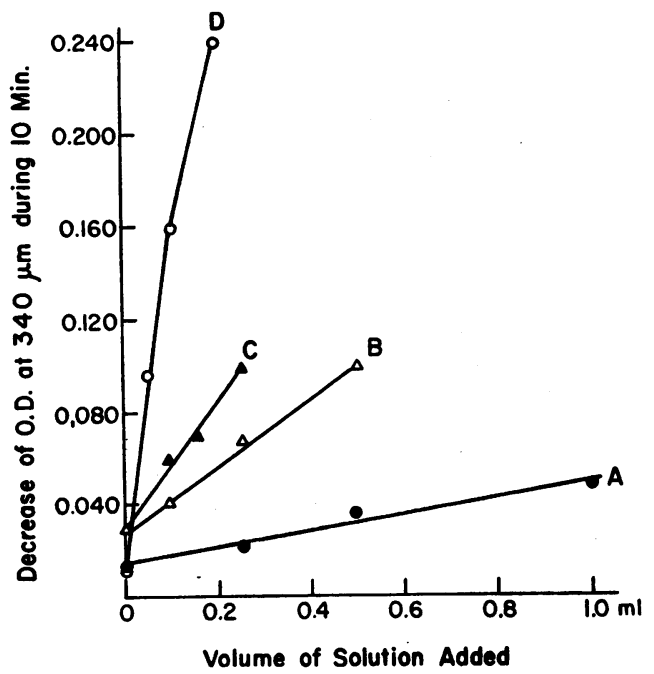

Fig. 2. EFFeCt of Nitrofurantoin, $\alpha$-NAPHThol, ASCORBIC ACID AND PRIMAQUINE ON TPNH OXIDATION IN THE PRESENCE OF DIAPHORASE FROM Cl. kluyveri: RELATIONSHIP TO VARYING CONCENTRATIONS OF THE COMPOUNDS. The assay mixture contains $0.15 \mu$ mole TPNH, diaphorase with an activity of $45 \mathrm{U}$ per $\mathrm{ml}$ prepared from $\mathrm{Cl}$. kluyveri, and one of the following compounds which is added as a solution in Krebs-Ringer phosphate buffer, $\mathrm{pH}$ 7.4: $\alpha$-naphthol and nitrofurantoin, saturated solutions (prepared as indicated in footnote to Table VII); primaquine phosphate, $2 \times 10^{-3} \mathrm{M}$; or ascorbic acid, $5.7 \times$ $10^{-2} \mathrm{M}$. The volume is made up to $3 \mathrm{ml}$ with the buffer solution. Curve A, $\alpha$-naphthol, diaphorase $0.45 \mathrm{U}$; curve $\mathrm{B}$, primaquine, diaphorase $0.9 \mathrm{U}$; curve $\mathrm{C}$, nitrofurantoin, diaphorase $0.9 \mathrm{U}$; curve $\mathrm{D}$, ascorbic acid, diaphorase 0.45 $\mathrm{U}$. The control assay mixture from which diaphorase is omitted shows no change in optical density. Control assay mixtures containing only TPNH and diaphorase show a slight decrease in optical density which is related to the diaphorase concentration. This decrease in optical density is indicated on the ordinate at zero abscissa value.

state between the oxidation of TPNH by ascorbic acid and diaphorase and the reduction of TPN by G6P and G6PD. Addition of more G6PD after the plateau is reached results in shifting this equilibrium toward a higher TPNH concentration. Similar results are obtained with nitrofurantoin, $\alpha$-naphthol and primaquine.

3) Preventing hemoglobin conversion to choleglobin. It has been reported that incubation of hemoglobin with ascorbic acid in the presence of oxygen results in its conversion to choleglobin, probably by a process of coupled oxidation and formation of hydrogen peroxide (38-41). Acetylphenylhydrazine and cysteine may also cause an oxidative breakdown of hemoglobin. Recently, 
Mills and Randall have reported purifying from red cells of rat and of cow a GSH peroxidase, which catalyzes the reduction of $\mathrm{H}_{2} \mathrm{O}_{2}$ by reduced glutathione $(\mathrm{GSH})$ leading to the formation of oxidized glutathione (GSSG) $(40,42,43)$. Addition of GSH or GSSG plus a system generating TPNH to hemolysates of rat erythrocytes prevented the conversion of hemoglobin to choleglobin by ascorbic acid. However, in the present study this mechanism could not be demonstrated in hemolysates prepared from human erythrocytes. Addition of GSH does not decrease the rate of choleglobin formation in the presence of ascorbic acid (Figure 4). Indeed, a slight increase in the rate of choleglobin formation was observed upon addition of GSH. ${ }^{1}$ TPNH does afford protection against choleglobin formation, but a similar activity was exerted by TPN. Thus, no specific requirement for the reduced form of TPN to prevent the conversion of hemoglobin to choleglobin could be demonstrated in hemolysates of human red cells.



Fig. 3. Reversal of the decrease in optical denSITY AT 340 M $\mu$ OF A MIXTURE OF TPNH, ASCORBIC ACID AND DIAPHORASE BY ADDITION OF G6P ANd G6PD. The initial assay mixture (from -5 to 0 minutes) contains $12 \mu$ moles of ascorbic acid and $0.45 \mathrm{U}$ of diaphorase prepared from $\mathrm{Cl}$. kluyveri. The control mixture contains no diaphorase (broken line). At zero time, $0.15 \mu$ mole of TPNH is added. At 20 minutes $0.5 \mathrm{ml}$ of $0.1 \mathrm{M}$ $\mathrm{MgCl}_{2}, 0.5 \mathrm{ml}$ of $0.01 \mathrm{M}$ G6P and $0.050 \mathrm{ml}$ of G6PD (containing $30 \mathrm{U}$ of enzyme activity) are added. This addition is associated with a decrease in optical density in both mixtures which probably reflects the dilution of the assay mixtures. At 36 minutes, an additional $60 \mathrm{U}$ of G6PD is added to both test and control mixtures.

1 Formation of oxidation products of hemoglobin upon incubation of crystalline hemoglobin with GSH has also been observed by Mills and Randall, but it was prevented by addition of purified GSH peroxidase (41).

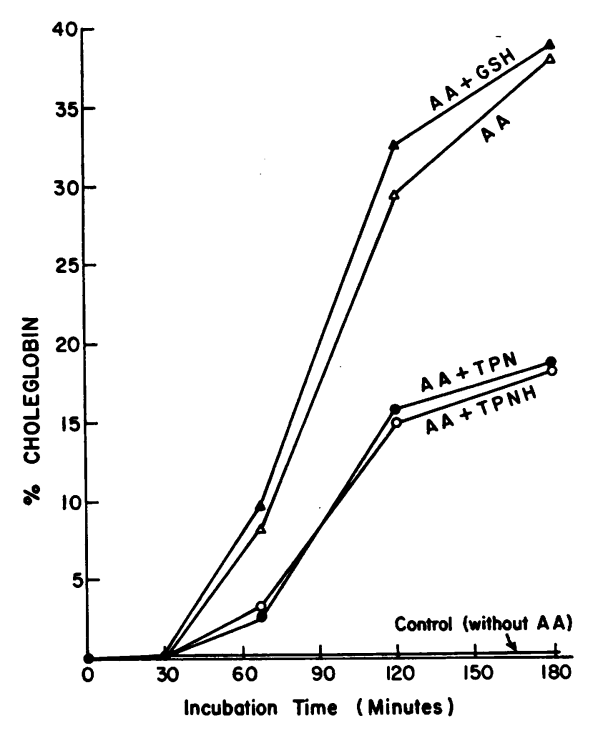

Fig. 4. The efFect of Pyridine NUCleotides AND OF GSH ON THE RATE OF CHOLEGLOBIN FORMATION IN THE PRESENCE OF ASCORBIC ACID. The incubation mixtures contain Krebs-Ringer phosphate solution, hemolysates prepared from normal human erythrocytes, and additions as indicated adjacent to each curve. The final concentrations of the reagents are: hemoglobin, $1.0 \mathrm{~g}$ per 100 $\mathrm{ml}$; ascorbic acid (AA), $2.8 \times 10^{-2} \mathrm{M}$; TPN and TPNH, $3.0 \times 10^{-4} \mathrm{M}$; and GSH, $1.0 \times 10^{-3} \mathrm{M}$. The final volume of the solution is $3 \mathrm{ml}$. The incubation is at $37^{\circ} \mathrm{C}$. A similar pattern of results, i.e., a decrease in the rate of choleglobin formation in the presence of TPN and TPNH, but not of GSH, is obtained with two additional sets of conditions. 1) Hemoglobin, $0.1 \mathrm{~g}$ per $100 \mathrm{ml}$; ascorbic acid, $7.2 \times 10^{-4} \mathrm{M}$; TPN and TPNH, $3.0 \times 10^{-4} \mathrm{M}$; and GSH, $8.0 \times 10^{-4} \mathrm{M}$. 2) Hemoglobin, $1.0 \mathrm{~g}$ per $100 \mathrm{ml}$; ascorb:c acid, $3.6 \times 10^{-3} \mathrm{M}$; TPN and TPNH, $3.0 \times 10^{-4} \mathrm{M}$; and GSH, $8.0 \times 10^{-4} \mathrm{M}$. The method of Lemberg, Legge and Lockwood (44) is used for choleglobin determination.

\section{DISCUSSION}

The present study indicates that the rate of oxidation of glucose via the pentose phosphate pathway may be selectively stimulated by cysteine, ascorbic acid or pyruvate, as well as by methylene blue, acetylphenylhydrazine, $\alpha$ - and $\beta$-naphthol, primaquine phosphate and nitrofurantoin. These observations suggest that among the determinants of the activity of the oxidative reactions of the pentose phosphate pathway in human erythrocytes in vivo may be the concentration of certain physiological substances, such as ascorbic acid and cysteine as well as a variety of agents or their metabolic products, to which the cells may become exposed. 
The mode of action of the various compounds in stimulating the rate of glucose catabolism via the pentose phosphate pathway may differ. This is suggested by the observation that conversion of hemoglobin to carboxyhemoglobin followed by incubation in an atmosphere of nitrogen affects to a different extent the stimulatory activity of the various compounds.

It is probable that the increase in the rate of oxidation of glucose to $\mathrm{CO}_{2}$ results from a more rapid rate of reoxidation of $\mathrm{TPNH}$ formed in the oxidative steps of the pentose phosphate pathway. It was found that cysteine may lead to a non-enzymatic oxidation of $\mathrm{TPNH}$, while nitrofurantoin, ascorbic acid, primaquine and $\alpha$-naphthol may cause TPNH oxidation in the presence of a suitable diaphorase. Scott and Griffith have purified a diaphorase from human erythrocytes, which catalyzes the reduction of methemoglobin by TPNH (although at a much slower rate than by $\mathrm{DPNH}$ ) (45). The activity of nitrofurantoin, ascorbic acid, $\alpha$-naphthol and primaquine in the presence of such a diaphorase from human erythrocytes has not yet been investigated. Such studies are necessary to determine the applicability of the present findings with plant or bacterial diaphorase in explaining the metabolic events in human erythrocytes. It is of interest that $\alpha$-naphthol and nitrofurantoin inhibit G6PD activity yet increase the rate of oxidation of glucose$1-\mathrm{C}^{14}$ to $\mathrm{C}^{14} \mathrm{O}_{2}$. This suggests that the inhibition of the activity of the enzyme by these agents is insufficient to make the enzyme activity rather than the concentration of TPN the factor limiting the rate of glucose oxidation by erythrocytes.

A number of investigators have concluded that the reoxidation of TPNH is the limiting factor in the rate of oxidation of glucose by the pentose phosphate pathway in a variety of tissues (4-12). This conclusion is based primarily on the observations that substances which may serve as electron acceptors from TPNH cause a marked increase in the rate of oxidation of glucose carbon atom 1 to $\mathrm{CO}_{2}$. The present findings are consistent with this hypothesis. In both normal cells and cells with a deficiency of G6PD, addition of compounds which can increase the rate of TPNH reoxidation is associated with an increase in the rate of oxidation of glucose to $\mathrm{CO}_{2}$. However, in the cells with low G6PD levels, the increment in the rate of glucose oxidation which may be achieved upon addition of the various stimulatory compounds appears to be limited by the activity of this enzyme.

There is another aspect of this stimulation of glucose catabolism via the pentose phosphate pathway which is of possible significance. A selective decrease in the activity of G6PD occurs as red cells age in vivo (46). Old erythrocytes, as well as cells with a genetically determined deficiency in G6PD (47) have an increased susceptibility to destruction under normal conditions and, particularly, upon exposure to a variety of agents including cysteine, acetylphenylhydrazine, nitrofurantoin, $\alpha$ - and $\beta$-naphthol, primaquine and the fava bean. This has suggested that the dehydrogenase reactions of the pentose phosphate pathway play an important role in the maintenance of the integrity of the red cell $(14,46,47)$. It is generally presumed that this is so because these reactions provide TPNH whose reductive potential, either directly or possibly through the generation of reduced glutathione, provides protection against the damaging effects of oxidative agents $(14,17$, $40-43,48-54)$. The present study suggests that one mechanism by which these substances could lead to a decreased survival time of red cells is by reoxidizing TPNH. In the cells with low levels of G6PD the capacity to generate TPNH may be inadequate to provide the necessary reductive potential to protect against the oxidative effects of these compounds. The finding that TPN or TPNH, but not GSH, could protect hemoglobin against denaturation to choleglobin in the presence of ascorbic acid suggests that the protection afforded by pyridine nucleotides need not be mediated through GSH. It has been demonstrated that TPN and TPNH, but not GSH, are important to the stability of proteins other than hemoglobin, e.g., G6PD $(32,55,56)$.

\section{SUM M ARY}

The rate of oxidation of glucose-1- $\mathrm{C}^{14}$ and of glucose-2- $\mathrm{C}^{14}$ to $\mathrm{C}^{14} \mathrm{O}^{2}$ by erythrocytes is stimulated by certain physiological substances such as cysteine, ascorbic acid and pyruvate, as well as by agents which can cause acute hemolytic anemias, namely, primaquine, nitrofurantoin, acetylphenylhydrazine, $\alpha$ - and $\beta$-naphthol and an extract of fava bean. 
This stimulation is more marked with cells with normal levels of glucose-6-phosphate dehydrogenase (G6PD) than with cells deficient in this enzyme. These compounds cause no increase in the rate of glucose utilization or in the rate of lactic acid formation.

The increased rate of catabolism of glucose via the pentose phosphate pathway caused by these agents is not a result of a direct effect on G6PD activity. Indeed, $\alpha$-naphthol and nitrofurantoin inhibit G6PD activity. Evidence has been obtained to suggest that the stimulation of the pathway is caused by an increased rate of reoxidation of TPNH in the presence of these compounds. A diaphorase-mediated oxidation of TPNH by nitrofurantoin, $\alpha$-naphthol, ascorbic acid and primaquine has been demonstrated. Cysteine can reoxidize TPNH even in the absence of a diaphorase. The increased rate of reoxidation of TPNH may be a factor in the mechanism by which these compounds lead to the destruction of aged red cells and erythrocytes with a genetically determined deficiency in G6PD.

\section{ACKNOWLEDGMENT}

The skillful help of Miss Theresa Fiorino is gratefully acknowledged.

\section{REFERENCES}

1. Szeinberg, A., and Marks, P. A. Study of the role of the pentose phosphate pathway in red cell metabolism. Clin. Res. 1960, 8, 248.

2. Murphy, J. R. Erythrocyte metabolism. II. Glucose metabolism and pathways. J. Lab clin. Med. 1960, 55, 286.

3. Johnson, A. B., and Marks, P. A. Glucose metabolism and oxygen consumption in normal and glucose-6-phosphate dehydrogenase deficient human erythrocytes. Clin. Res. 1958, 6, 187.

4. Dickens, F. Part II. Enzymes in red blood cells. Recent advances in knowledge of the hexose monophosphate shunt. Ann. N. Y. Acad. Sci. 1958, 75, 71.

5. Holzer, H. Carbohydrate metabolism. Ann. Rev. Biochem. 1959, 28, 171.

6. deDuve, C., and Hers, H. G. Carbohydrate metabolism. Ann. Rev. Biochem. 1957, 26, 149.

7. Brin, M., and Yonemoto, R. H. Stimulation of the glucose oxidative pathway in human erythrocytes by methylene blue. J. biol. Chem. 1958, 230, 307.

8. McLean, P. Carbohydrate metabolism of mammary tissue. III. Factors in the regulation of pathways of glucose catabolism in the mammary gland of the rat. Biochim. biophys. Acta 1960, 37, 296.
9. Cahill, G. F., Jr., Hastings, A. B., Ashmore, J., and Zottu, S. Studies on carbohydrate metabolism in rat liver slices. X. Factors in the regulation of pathways of glucose metabolism. J. biol. Chem. 1958, 230, 125 .

10. Kinoshita, J. H. The stimulation of the phosphogluconate oxidation pathway by pyruvate in bovine corneal epithelium. J. biol. Chem. 1957, 228, 247.

11. Wenner, C. E. Oxidation of reduced triphosphopyridine nucleotide by ascites tumor cells. J. biol. Chem. 1959, 234, 2472.

12. Holzer, H., and Witt, I. Beschleunigung des oxydativen Pentosephosphatcyclus in Hefezellen durch Ammoniumsalze. Biochim. biophys. Acta 1960, 38, 163.

13. Rall, T. W., and Lehninger, A. L. Glutathione reductase of animal tissues. J. biol. Chem. 1952, 194, 119.

14. Beutler, E. The hemolytic effect of primaquine and related compounds: A review. Blood 1959, 14, 103.

15. Zinkham, W. H., and Childs, B. A defect of glutathione metabolism in erythrocytes from patients with a naphthalene-induced hemolytic anemia. $\mathrm{Pe}$ diatrics 1958, 22, 461.

16. Kimbro, E. L., Jr., Sachs, M. V., and Torbert, J. V. Mechanism of the hemolytic anemia induced by nitrofurantoin (Furadantin). Further observations on the incidence and significance of "primaquinesensitive" red cells. Bull. Johns Hopk. Hosp. 1957, 101, 245.

17. Szeinberg, A., Adam, A., Ramot, B., Sheba, C., and Myers, F. The incorporation of isotopically labelled glycine into glutathione of erythrocytes with glucose-6-phosphate dehydrogenase deficiency. Biochim. biophys. Acta 1959, 36, 65.

18. Walker, D. B., and Bowman, J. E. In vitro effect of Vicia faba extracts upon reduced glutathione of erythrocytes. Proc. Soc. exp. Biol. (N. Y.) 1960, 103, 476.

19. Mela, C., and Perona, G. P. Sulla resistenza in vitro del glutatione ridotto eritrocitario al succo di fave fresche; nota preventiva. Boll. Soc. ital. Biol. sper. 1959, 35, 146.

20. Marks, P. A., Gellhorn, A., and Kidson, C. Lipid synthesis in human leukocytes, platelets, and erythrocytes. J. biol. Chem. 1960, 235, 2579.

21. Cohen, P. P. in Umbreit, W. W., Burris, R. H., and Stauffer, J. F. Manometric Techniques and Related Methods for Study of Tissue Metabolism. Minneapolis, Burgess Publishing, 1957, p. 149.

22. Passmann, J. M., Radin, N. S., and Cooper, J. A. D. Liquid scintillation technique for measuring carbon-14-dioxide activity. Analyt. Chem. 1956, 28, 484.

23. Horn, H. D., and Bruns, F. H. Quantitative Bestimmung von $\mathrm{L}(+)-$ Milchsäure mit Milchsäuredehydrogenase. Biochim. biophys. Acta 1956, 21, 378. 
24. Somogyi, M. A method for the preparation of blood filtrates for the determination of sugar. J. biol. Chem. 1930, 86, 655.

25. Timell, T. E., Glaudemans, C. P. J., and Currie, A. L. Spectrophotometric method for determination of sugars. Analyt. Chem. 1956, 28, 1916.

26. Scott, T. A., Jr., and Melvin, E. H. Determination of dextran with anthrone. Analyt. Chem. 1953, 25, 1656.

27. Rappaport, F. Rapid Microchemical Methods for Blood and C.S.F. Examinations. New York, Grune and Stratton, 1942, p 242.

28. Saifer, A., and Gerstenfeld, S. The photometric microdetermination of blood glucose with glucose oxidase. J. Lab. clin. Med. 1958, 51, 448.

29. Kornberg, A., and Horecker, B. L. Glucose-6- phosphate dehydrogenase in Methods in Enzymology, S. P. Colowick and N. O. Kaplan, Eds. New York, Academic Press, 1955, vol. 1, p. 323.

30. Horecker, B. L., and Smyrniotis, P. Z. Phosphogluconic acid dehydrogenase from yeast. J. biol. Chem. 1951, 193, 371.

31. Marks, P. A., and Gross, R. T. Erythrocyte glucose-6-phosphate dehydrogenase deficiency: Evidence of differences between Negroes and Caucasians with respect to this genetically determined trait. J. clin. Invest. 1959, 38, 2253.

32. Marks, P. A., Szeinberg, A., and Banks, J. Erythrocyte glucose-6-phosphate dehydrogenase of normal and mutant human subjects. J. biol. Chem. 1961, 236, 10.

33. Avron, M., and Jagendorf, A. T. A TPNH diaphorase from chloroplasts. Arch. Biochem. 1956, $65,475$.

34. Rubinstein, D., Ottolenghi, P., and Denstedt, O. F. The metabolism of the erythrocyte. XIII. Enzyme activity in the reticulocyte. Canad. J. Biochem. 1956, 34, 222.

35. Stein, W. H., and Moore, S. The free amino acids of human blood plasma. J. biol. Chem. 1954, 211, 915.

36. Wroblewski, F., and LaDue, J. S. Lactic dehydrogenase activity in blood. Proc. Soc. exp. Biol. (N. Y.) 1955, 90, 210.

37. Desforges, J. F., Kalaw, E., and Gilchrist, P. Inhibition of glucose-6-phosphate dehydrogenase by hemolysis inducing drugs. J. Lab. clin. Med. 1960, 55, 757.

38. Lemberg, R., and Legge, J. W. Hematin Compounds and Bile Pigments. New York, Interscience Publishers, 1949, p. 476.

39. Kaziro, K., Kikuchi, G., and Kawai, M. Reaction of verdohemoglobin formation in vitro, with spe:ial reference to its quantitative treatment. J. Biochem. (Tokyo) 1956, 43, 161.

40. Mills, G. C. Hemoglobin catabolism: I. Glutathione peroxidase, an erythrocyte enzyme which protects hemoglobin from oxidative breakdown. J. biol. Chem. 1957, 229, 189.
41. Mills, G. C., and Randall, H. P. Hemoglobin catabolism: The protection of hemoglobin from oxidative breakdown in the intact erythrocyte. J. biol. Chem. 1958, 232, 589.

42. Mills, G. C. The purification and properties of glutathione peroxidase of erythrocytes. J. biol. Chem. 1959, 234, 502.

43. Mills, G. C. Glutathione peroxidase and the destruction of hydrogen peroxide in animal tissues. Arch. Biochem. 1960, 86, 1.

44. Lemberg, R., Legge, J. W., and Lockwood, W. H. Coupled oxidation of ascorbic acid and haemoglobin. 3. Quantitative studies on choleglobin formation. Estimation of haemoglobin and ascorbic acid oxidation. Biochem. J. 1941, 35, 339.

45 Scottt, E. M., and Griffith, I. V. The enzymic defect of hereditary methemoglobinemia: Diaphorase. Biochim. biophys. Acta 1959, 34, 584.

46. Marks, P. A., Johnson, A. B., and Hirschberg, E. Effect of age on the enzyme activity in erythrocytes. Proc. nat. Acad. Sci. (Wash.) 1958, 44, 529.

47. Carson, P. E., Flanagan, C. L., Ickes, C. E., and Alving, A. S. Enzymatic deficiency in primaquine-sensitive erythrocytes. Science 1956, 124, 434.

48. Keilin, D., and Hartree, E. F. Spectroscopic study of permeability and lysis of red blood corpuscles. Nature (Lond.) 1946, 157, 210.

49. Fegler, G. Relationship between reduced glutathione content and spontaneous haemolysis in shed blood. Nature (Lond.) 1952, 170, 624.

50. Benesch, R. E., and Benesch, R. Relation between erythrocyte integrity and sulfhydryl groups. Arch. Biochem. 1954, 48, 38.

51. Beutler, E., Robson, M., and Buttenwieser, E. The mechanism of glutathione destruction and protection in drug-sensitive and nonsensitive erythrocytes. In vitro studies. J. clin. Invest. 1957, 36, 617.

52. Horecker, B. L., and Hiatt, H. H. Pathways of carbohydrate metabolism in normal and neoplastic cells. New Engl. J. Med. 1958, 258, 177 and 225.

53. Marks, P. A. Red cell glucose-6-phosphate and 6-phosphogluconic dehydrogenases and nucleoside phosphorylase. Science 1958, 127, 1338.

54. Jandl, J. H., Engle, L. K., and Allen, D. W. Oxidative hemolysis and precipitation of hemoglobin. I. Heinz body anemias as an acceleration of red cell aging. J. clin. Invest. 1960, 39, 1818.

55. Marks, P. A., Banks, J., and Gross, R. T. Glucose-6phosphate dehydrogenase thermostability in leukocytes of Negroes and Caucasians with erythrocyte deficiency of this enzyme. Biochem. biophys. Res. Com. 1959, 1, 199.

56. Kirkman, H. N. Characteristics of glucose-6-phosphate dehydrogenase from normal and primaquinesensitive erythrocytes. Nature (Lond.) 1959, 184, 1291. 